\title{
Protección contra la exposición al humo de tabaco ajeno: recomendaciones de la OMS
}

\author{
Armando Peruga, MC, PHD. ${ }^{(1)}$
}

$\mathrm{D}$ urante los últimos años, se acumuló bastante evidencia cient fica sobre el impacto de la exposición al humo de tabaco ajeno* (HTA) en la salud, as como sobre los beneficios de los ambientes libres de humo de tabaco (ALHT) y las mejores prácticas para hacerlos realidad. Transmitir esta información es vital, por una parte, para concienciar a los sectores pol tico y de salubridad sobre la necesidad de aumentar los ALHT en espacios interiores para proteger la salud de los trabajadores y del público en general y, por otra, para que dichos ambientes sean considerados normales, respaldados e incluso reclamados por la población, como está ocurriendo en un número considerable y cada vez mayor de localidades.

Las obligaciones contenidas en el Convenio Marco de la OMS para el Control del Tabaco, del que más de 140 pa ses forman parte en la actualidad, han alentado a la OMS a proveer pautas claras sobre la protección contra el HTA. El mismo art culo 8 de este convenio establece:

Cada Parte ${ }^{\ddagger}$ adoptará y aplicará, en áreas de la jurisdicción nacional existente y conforme determine la legislación nacional, medidas legislativas, ejecutivas, administrativas y/u otras medidas eficaces de protección contra la exposición al humo de tabaco en lugares de trabajo interiores, medios de transporte público, lugares públicos cerrados y, según proceda, otros lugares públicos, y promoverá activamente la adopción y aplicación de esas medidas en otros niveles jurisdiccionales. ${ }^{1}$

\footnotetext{
* El humo de tabaco ajeno también se conoce como humo del tabaco de los demás, humo de tabaco de segunda mano o humo de tabaco ambiental, y la persona expuesta al mismo se denomina a veces fumador pasivo.

‡ Estado miembro de la OMS que ha ratificado el convenio.
}

Por todo lo anterior, la OMS ha considerado oportuno efectuar recomendaciones públicas sobre protección contra la exposición al HTA.

\section{El desarrollo de las recomendaciones}

La OMS convocó a una consulta mundial de expertos en Montevideo, con el apoyo de su Centro Colaborador sobre vigilancia y evaluación del Instituto para el Control Mundial del Tabaco, situado en la Escuela de Salud Pública Johns Hopkins Bloomberg. El propósito de esta consulta, celebrada en noviembre de 2005, fue reunir a los expertos para dilucidar las bases cient ficas que permitieran realizar recomendaciones a partir de las evidencias surgidas en los temas siguientes:

- $\quad$ los efectos del HTA sobre la salud y el costo económico de exponerse a él;

- el impacto de los ALHT sobre el consumo de tabaco, la salud y la econom a;

- $\quad$ el desarrollo y la aplicación de pol ticas adecuadas, $\mathrm{y}$

- las necesidades y los recursos disponibles para crear ALHT.

Las recomendaciones de la OMS están basadas, en parte, en los resultados de esta consulta, que posteriormente fueron ampliados por otros expertos que representan experiencias de todos los rincones del mundo y muy diversas disciplinas cient ficas. El Centro Colaborador en pol ticas de control de tabaco de la Universidad de California en San Francisco, por ejemplo, participó activamente en este proceso junto con el Centro Colaborador de Johns Hopkins.

(I) Organización Mundial de la Salud, Ginebra.

Fecha de aceptado: 20 de abril de 2007

Solicitud de sobretiros: Dr.Armando Peruga. Tobacco Free Initiative. World Health Organization. Avenue Appia 20, CH I2I I, Ginebra 27, Suiza. Correo electrónico: PerugaA@who.int 


\section{EI humo de tabaco ajeno mata}

Es incontestable que no hay ninguna concentración por debajo de la cual la exposición al HTA sea segura. Existe un claro consenso cient fico sobre los peligros de ésta para la salud, basado tanto en la evidencia acumulada durante años como en los nuevos datos. No hay ninguna duda de que el HTA produce enfermedades graves y letales en adultos y niños. Varios informes recientes, como la monograf a de 2004 de la Agencia Internacional para la Investigación del Cáncer de la OMS, ${ }^{2}$ el informe de 2005 de la Agencia de Protección Ambiental de California ${ }^{3}$ y el informe de 2006 del Cirujano General de los Estados Unidos, ${ }^{4}$ han examinado todas las pruebas cient ficas existentes y llegado a la firme conclusión de que la exposición al HTA mata, por lo que se vuelve imperativo eliminarla en todos los lugares públicos y de trabajo interiores, donde gran parte de la población mundial pasa muchas horas al $\mathrm{d}$ a.

\section{Los ambientes libres de humo de tabaco, la única solución}

Dado que no hay ningún grado seguro de exposición al HTA ni tampoco ninguna tecnolog a de tratamiento del aire que la reduzca a valores seguros o confortables, la única solución es impedir que se produzca humo de tabaco. Desde este punto de vista, gobiernos locales, estatales y nacionales de todo el mundo se han lanzado a crear pol ticas de ALHT en lugares públicos y de trabajo interiores para protección de todos.

Las jurisdicciones que han aplicado estas pol ticas comprobaron una reducción inmediata en las concentraciones de HTA en el aire de los locales cerrados, una reducción de las concentraciones de los componentes de éste en el cuerpo de los afectados y una mejora significativa e inmediata de la salud de los trabajadores previamente expuestos al mismo. Por otra parte, se ha demostrado que los ALHT contribuyen en gran medida a facilitar que los fumadores dejen de fumar o que al menos disminuyan su consumo y que los no fumadores no empiecen a fumar. Además, la legislación que ordena la creación de ALHT cuenta con un gran apoyo popular y se cumple con facilidad cuando se aplica de manera adecuada. En última instancia, los ALHT env an un mensaje claro de que el fumar no goza de aceptación social.

\section{Enseñanzas prácticas}

Las recientes experiencias de demarcaciones nacionales y subnacionales a lo largo y ancho del mundo han puesto de manifiesto la factibilidad de crear ALHT, y el interés por promocionarlos ha aumentado. Pa ses desarrollados y en $v$ as de desarrollo por igual, como Gambia, Irlanda, Nueva Zelanda y Uruguay, y territorios tales como las Bermudas, han creado ALHT con base en las prácticas de los municipios y provincias de Norteamérica que empezaron a aplicar leyes sobre ALHT en los años finales de la década de los 70 . Hoy, más de 10 pa ses y cientos de jurisdicciones locales y subnacionales pueden considerarse totalmente libres de humo de tabaco. En todas estas jurisdicciones se han aprobado y aplicado con éxito, as como con gran apoyo social, normas legales que protegen a trabajadores y público en general en casi todos los lugares públicos y de trabajo interiores, incluidos bares y restaurantes. Otros pa ses denotan sumo interés en aprender de sus acciones.

Estas experiencias ofrecen una serie de enseñanzas de las que vale la pena tomar buena nota para asegurar la aplicación exitosa de las mejores pol ticas posibles y, de esta manera, proteger a la población del HTA. A saber:

- Los ALHT deben ser creados mediante normas legales para proteger con efectividad la salud pública. Los acuerdos voluntarios no funcionan.

- Las normas legales deben ser sencillas y claras para que se puedan aplicar y hacer cumplir sin dificultad. Las normas que establecen ALHT en todos los lugares públicos y de trabajo sin excepciones son las más claras y sencillas.

- Las organizaciones de la sociedad civil deben presentar un involucramiento pleno para lograr que se aprueben y apliquen normas legales efectivas sobre ALHT.

- La aplicación de las normas legales sobre ALHT requiere siempre consultar y educar al público.

- Hacer cumplir las normas legales sobre ALHT exige un plan por parte de las autoridades correspondientes, además de una infraestructura y un presupuesto, que, as sean relativamente pequeños, son esenciales.

- $\quad$ La puesta en marcha de ALHT debe ser monitoreada para documentar sus frutos y disipar los recelos que aún puedan quedar tras su creación.

Una última enseñanza de gran importancia es que hay que prepararse y responder a la oposición que monta la industria del tabaco, de manera habitual por intermedio de terceras partes, contra la aprobación de normas legales sobre ALHT. Desde la década de los 70, esta industria considera que las normas legales que crean ALHT son "el acontecimiento más peligroso para la viabilidad de la industria tabacalera que jamás haya ocurrido". 5 La industria tabacalera, que suele operar mediante grupos pantalla, se opone con vigor a la crea- 


\section{La efectividad de las ALHT según la propia industria tabacalera}

“...Hacía tiempo que los argumentos económicos usados de manera habitual por la industria tabacalera para ahuyentar las actividades dirigidas a prohibir fumar habían perdido eficacia, si es que alguna vez tuvieron algún efecto. Estos argumentos simplemente no eran creíbles, lo cual no es de sorprender si consideramos que rara vez se hicieron realidad las terribles predicciones que hacíamos." - Philip Morris, 1994, Cita: http://legacy.library.uscf.edutid/vnf77e00

"Los que dicen trabajar en lugares donde fumar está restringido, fuman I.25 cigarrillos menos que los que lo hacen en trabajos donde no lo está. Ese cigarrillo y cuarto menos por día representa 7000 millones menos de cigarrillos fumados por año a causa de las ALHT. Eso significa 350 millones de paquetes de cigarrillos. A un dólar por paquete, la más mínima restricción en el lugar de trabajo le cuesta a esta industria 233 millones de dólares anuales de ingresos". - United States Tobacco Institute 1985, Cita: http://legacy.library. ucsf.edu/tid/owo03f00

ción de ALHT mediante normas legales. Las tabacaleras siguen tergiversando la evidencia cient fica sobre los peligros del HTA para la salud e incluso proclaman que la OMS dice que el HTA no es peligroso. De hecho, la OMS siempre afirmó lo contrario: el HTA mata.

\section{Las recomendaciones de la OMS}

A la luz de la evidencia cient fica y las experiencias existentes, la OMS emite las siguientes recomendaciones para proteger la salud de trabajadores y público en general de los peligros de la exposición al HTA.

1. Impida que el humo de tabaco contamine el aire de los espacios interiores mediante la creación de ambientes totalmente libres de humo de tabaco. Ésta es la única solución eficaz para reducir a valores seguros la concentración de HTA y proveer un grado aceptable de protección frente al peligro que supone estar expuesto a tal humo. Ni los sistemas de ventilación ni los espacios designados para fumar, aun en el caso de que estén ventilados en forma separada, reducen la exposición al HTA a concentraciones seguras y no se recomiendan bajo ninguna circunstancia.

2. Apruebe normas legales que obliguen a que todos los lugares públicos y de trabajo interiores sean libres de humo de tabaco. Estas normas legales deben asegurar una protección universal e igual para todos. Las pol ticas voluntarias no son una respuesta aceptable para ofrecer la protección necesaria. En algunas circunstancias el principio de protección universal pudiera implicar que algunos lugares semiabiertos o abiertos deban ser declarados ALHT.

3. Aplique y haga cumplir las normas legales. Aprobar normas legales sobre ALHT no es suficiente. Para aplicarlas en forma adecuada se requieren esfuerzos y medios relativamente pequeños pero esenciales.

4. Aplique estrategias de educación para reducir la exposición al HTA en los hogares y reconozca que las normas legales que hacen de los lugares de trabajo espacios totalmente libres de humo aumentan la probabilidad de que los fumadores y no fumadores protegidos por estas normas también conviertan sus casas en libres de humo.

En resumen, estas recomendaciones son una respuesta a los incuestionables peligros del HTA y una oportunidad para guiar a un número creciente de jurisdicciones interesadas en crear ALHT. La OMS alienta a sus estados miembros a seguir estas recomendaciones y a poner en práctica las enseñanzas adquiridas en otras jurisdicciones para proteger la salud pública. Para llamar la atención sobre la urgencia de estas medidas, el D a Mundial sin Tabaco de 2007 está dedicado a promover los ambientes $100 \%$ libres de humo de tabaco. El lema de este año: libres de humo por dentro, crear y disfrutar ambientes $100 \%$ libres de humo de tabaco, recuerda que todos podemos hacer algo para lograrlo y que los legisladores pueden hacer una contribución decisiva.

\section{Referencias}

I.World Health Organization, Framework Convention on Tobacco Control, Article 8.2. Geneva:WHO, 2003.

2. Tobacco smoke and involuntary smoking: summary of data reported and evaluation. Lyon, International Agency for Research on Cancer, 2004 (IARC Monographs, Vol. 83).

3. Proposed Identification of Environmental Tobacco Smoke as a Toxic Air Contaminant, SRP Approved Version. Part B: Health Effects. California Environmental Protection Agency, 24 de junio de 2005 [consultado en enero 4 de 2007]. Disponible en: http://www.arb.ca.gov/toxics/ets/ finalreport/finalreport.htm

4. The Health Consequences of Involuntary Exposure to Tobacco Smoke: A Report of the Surgeon General. Atlanta, United States Department of Health and Human Services, Centers for Disease Control and Prevention, Coordinating Center for Health Promotion, National Center for Chronic Disease Prevention and Health Promotion, Office on Smoking and Health, 2006.

5.A study of public attitudes toward cigarette smoking and the tobacco industry in 1978. Roper Organization, Volume I. Prepared for the Tobacco Institute, 1978 [consultado en enero 4 de 2007]. Disponible en: http://legacy.library.ucsf.edu/tid/yuf 9200 